\title{
Reflexões sobre a Ética na Educação Escolar
}

\author{
Reflections on Ethics in School Education
}

Renato José Oliveira*

Universidade Federal do Rio de Janeiro

Resumo Este artigo discute a ética na educação escolar hoje. Parte das visões de pensadores como Kant e Stuart Mill sobre o agir ético e as problematiza, com base no modelo argumentativo proposto por Chaïm Perelman, o qual critica as concepções que defendem o caráter unitário da verdade (monismos). Tal crítica o aproxima dos discursos questionadores do modelo tradicional de educação, que desconsidera o aluno como sujeito do diálogo. A ética é, então, pensada a partir de uma postura pedagógica que, ao invés de prescrever o que é "certo" ou "justo", privilegia a problematização do pensar e do agir. Esta se dá por meio do confronto entre argumentos, que debatem valores e formas de conduta, contribuindo, assim, para evitar a ocorrência de posturas dogmáticas e discriminatórias no ambiente escolar.

PALAVRAS-CHAVE: Ética, Educação Escolar, Argumentação.

Abstract This article discusses ethics in school education nowadays. It starts from visions of thinkers like Kant and Stuart Mill on ethical action which are discussed on the basis of the argumentative model proposed by Chaïm Perelman, who criticizes the conceptions that defend the unitary character of truth (monisms). This critical vision approximates it from inquisitive speeches of the traditional model of education, which disregards the student as subject of dialogue. Ethics is thought, therefore, in a view of pedagogical work attitude which, instead of prescribing what is "right" or "fair", favours the problematization of thinking and acting. This one occurs through the confrontation between arguments that discuss values and forms of conduct, thereby contributing to avoid dogmatic and discriminatory attitudes in the school environment

KEYWORDS: Ethics, School Education, Argument. 


\section{Introdução}

Principalmente a partir dos anos 1990, a ética vem sendo discutida nas escolas brasileiras. Publicações como os Parâmetros Curriculares Nacionais do Ensino Fundamental (PCN) em 1998, os Parâmetros Curriculares Nacionais do Ensino Médio (PCNEM) em 2000, e as Diretrizes Curriculares Nacionais da Educação Básica (DCN) em 2010 são alguns marcos importantes desse processo. Um aspecto que tem chamado a atenção é a expectativa de que o trabalho com a ética, no ambiente escolar, funcione como espécie de "antídoto" contra a indisciplina e a violência crescentes, o consumo de drogas e a gravidez precoce. Mas o que pode ser entendido por ética?

Segundo destacou Kant em fins do século XVIII, o estatuto das regras que regulam a vontade particular deve ser sempre aferido a partir da pergunta: aquilo que considero válido para definir minha conduta individual poderia ser convertido em lei válida para todos os homens? Na visão kantiana, a condição de sujeito ético seria alcançada somente quando a vontade do praticante coincidisse plenamente com a forma pura da lei moral (imperativo categórico), não tendo outro fim que o dever em si mesmo: "Age de tal modo que a máxima da tua vontade possa valer sempre ao mesmo tempo como princípio de uma legislação universal” (KANT, 1997a, p. 42).

A lei moral não admite transgressões, de sorte que pensar sempre no bem da humanidade, deixando de lado os interesses contingentes, oriundos da realidade empírica, seria uma condição necessária. A título de contraponto, a ética utilitarista de Stuart Mill (século XIX) sustenta que a lei maior a ser respeitada prescreve que "iguais quantidades de felicidade são igualmente desejáveis, sejam sentidas pela mesma pessoa ou por pessoas diferentes" (MILL, 2005, p. 126). Este é o chamado princípio de utilidade, o qual flexibiliza o rigor da concepção kantiana, admitindo que "para salvar uma vida, pode ser não apenas permissível, mas um dever, roubar, ou tomar pela força a comida ou os medicamentos necessários, ou raptar o único médico competente e forçá-lo a exercer" (Ibid., p. 128).

Embora considere a facticidade inerente à vida social, a proposta de Mill esbarra na dificuldade de quantificar a felicidade, pois esta não pode ser traduzida em números. Como então determinar as "iguais quantidades" prescritas pelo princípio de utilidade? Buscando investigar as limitações que os princípios gerais ensejam, Chaïm Perelman (1912-1984) salienta que "os diferentes princípios de moral não são contestados por homens que pertencem a meios de cultura diferentes, mas são interpretados de modos diversos, não sendo jamais definitivas essas tentativas de interpretação" (PERELMAN, 2005, p. 297). Em vista disso, propõe a argumentação como via possível de entendimento, desde que os envolvidos aceitem debater suas diferentes visões de mundo e os valores que lhes dão suporte.

$\mathrm{Na}$ medida em que os problemas que cercam a vida prática dos homens remetem a questões de natureza, tanto ontológica quanto deontológica, a ética pode ser tomada como construto que põe em exame valores, hierarquias de valores, princípios gerais e formas de conduta que orientam as ações dos homens no contexto de suas múltiplas relações. Esse construto, por ser histórico, social, cultural e intersubjetivo não precisa recorrer a uma norma transcendente que possua o estatuto de fundamento universal, mas estabelece seus fundamentos normativos "no espaço intramundano, no que é ordinário ou que representa a maioria dos casos, naquilo que é referendado pelo consenso da maioria" (SAMARANCH, 1991, p. 239). 
$\mathrm{Na}$ escola de hoje, pode-se observar que muitos hábitos e atitudes exibidos pelos discentes, considerados consensuais no passado, não o são mais, sendo necessário, portanto, colocar em discussão os valores que os balizam, bem como não desconhecer as histórias de vida dos alunos. Se tal diálogo não for aberto, o "certo" e o "errado" tendem a ser absolutizados, gerando, muitas vezes, posturas dogmáticas e discriminatórias. Com o intuito de evitá-las, o presente artigo defende que, no ambiente escolar, se promova o debate entre concepções que tenham diferentes visões do bem, do verdadeiro e do justo.

Nessa perspectiva, Perelman e Olbrechts-Tyteca (2005) destacaram a importância da argumentação como construto humano-social que visa à adesão de outrem com respeito às teses que são submetidas ao seu assentimento. Para os autores, persuadir, por meio de razões que mostrem porque uma tese é preferível à outra, é um procedimento legítimo, nada tendo em comum com as práticas demagógicas cuja finalidade é apenas levar os indivíduos à ação a partir do apelo às suas paixões e interesses imediatos. Trata-se, portanto, de assumir uma postura dialógica que, no tocante à escola, contribua para o exercício do convívio democrático entre os diferentes sujeitos envolvidos nas práticas educativas.

\section{Ética argumentativa: contraponto as visões unitárias da verdade}

Para o homem ocidental, a busca do Bem, da Justiça e da Verdade sempre foi um objetivo a conquistar. Platão considerava tais valores supremos, porém só alcançáveis por aqueles que tivessem condição de perseguí-los a exaustão: os verdadeiros filósofos. Estes, por possuíem almas nobres e terem passado por um longo programa de estudos, superariam os obstáculos interpostos à inteligência pelo mundo sensível, marcado pelas opiniões errôneas, pelas paixões e por toda a sorte de interesses mesquinhos. Sua tarefa maior seria governar a cidade, atuando como guias voltados para orientar os cidadãos na prática do bem:

Mas vós fostes formados conforme o interesse do Estado para serdes reis da colméia e de vós mesmos. Recebestes educação melhor e mais perfeita que os filósofos de outras cidades e estais, portanto, mais capacitados para o exercício da vida pública. É preciso, pois, que desçais à morada subterrânea onde vivem os demais homens e que vos acostumeis às trevas que reinam lá. Uma vez acostumados, vereis mil vezes melhor que eles e conhecereis cada imagem e o que ela representa, já que contemplastes o belo, o justo e o bem em sua verdadeira essência. Assim, o governo da cidade será realidade e não um sonho vão como os governos das cidades atuais, onde os governantes se batem uns contra os outros e disputam o poder, que veneram como um grande bem. (PLATÃO, 1966, p. 278-9)

$\mathrm{Na}$ visão platônica, conhecer a forma perfeita do Bem permitiria à classe governante combater a cegueira e a ignorância responsáveis pelos males e injustiças. $\mathrm{O}$ Estado perfeito seria aquele em que as relações hierárquicas entre governantes e governados fossem aceitas de bom grado, respeitando-se o princípio de eunomia, segundo o qual cada classe componente da sociedade desempenharia as funções correspondentes as suas aptidões. Assim, aos reis filósofos caberia o governo, aos guerreiros as funções relacionadas à defesa da cidade e aos demais cidadãos os diferentes serviços (produção 
de artefatos, comércio, agricultura, etc.) necessários à manutenção da vida social. A quebra de tais relações implicaria desarmonia e confusão, analogamente ao que ocorre nas almas dos indivíduos perturbados. Platão (2008) compara a alma humana a uma parelha de cavalos guiada por um cocheiro. Um dos animais, a boa vontade, é dócil e obedece de bom grado ao cocheiro (governante) enquanto o outro, a concupiscência, é rebelde e, quando se revolta, torna muito difícil a condução do coche.

Perelman (1979) chama tais concepções de monismos ${ }^{1}$, cujos propósitos são oferecer visões sistematizadas e racionalizadas do mundo. Para lograr seus fins, entretanto, muitas vezes operam com reducionismos inaceitáveis, justificando em nome da Razão, da Fé ou do interesse do Estado a prática da violência contra os opositores, que se não forem convencidos de seus erros, deverão ser punidos.

Contrapondo-se aos monismos, Perelman advoga que nenhum credo - político, religioso, científico, ético, estético - possui o monopólio da verdade. Há razões mais ou menos verossímeis que dão suporte às crenças, aos princípios, aos costumes, mas elas não se impõem com base em nenhuma autoridade situada acima dos homens: é o debate, a negociação entre eles, conduzida por meio de argumentos, que deve conquistar adesões, estabelecendo, inclusive, os critérios de normalidade.

$\mathrm{Na}$ medida em que se volta para os costumes e as formas de conduta, a ética se depara constantemente com a alteridade, sendo necessário debater diferentes visões. Tendo em vista que o homem é um ser movido por razões e paixões, cada um de nós pode ser considerado como interlocutor disputado por diferentes vozes: a do útil, a da normalidade, a do sonho, a da nostalgia e outras mais. As diversas relações que mantemos (familiares, comunitárias, profissionais, etc.) atuam no sentido de amplificar ou reduzir essas vozes, permitindo problematizar o que significa agir como sujeito ético. Um modo de problematizar consiste em questionar, por exemplo, a universalidade de valores como o Bem e o Verdadeiro, os quais só gozam desse estatuto quando seus conteúdos concretos não são precisados. Assim, a afirmação "todos devem fazer o bem" é objeto de concordância em abstrato, mas as divergências logo surgem quando perguntamos a uns e a outros que sentidos conferem ao bem.

Para Perelman (2005), embora as posturas éticas não sejam definíveis com base em razões que convencerão igualmente a todos os homens, também não são meramente contingentes. São construções humano-sociais marcadas por diferentes fatores e interesses, sendo os processos argumentativos os meios pelos quais se sustenta ou refuta a natureza ética de uma ação. A partir deles, é possível negociar as distâncias que, por razões culturais, sociais ou religiosas separam os indivíduos, levando-os a estabelecer novos acordos normativos, ainda que provisórios. Retirar da ética o caráter universal e absoluto que a caracteriza como monismo não significa proclamar o relativismo axiológico; é, antes, um meio de chamar a atenção para o fato de que toda construção humana é controversa e, portanto, se torna objeto de dúvidas e de questionamentos.

$\mathrm{Na}$ medida em que, na visão perelmaniana, a ética não resulta de procedimentos indutivos nem dedutivos, a ciência do Direito, baseada no embate argumentativo entre teses rivais, se coloca como um referente. De forma semelhante ao que ocorre nos processos judiciais, as discussões que estabelecem as normas éticas poderão ser reabertas quando novos elementos surgirem. Existe, portanto, uma tensão dialética 
entre o formalismo e a facticidade, entre a deontologia e a ontologia, entre os princípios e os juízos:

Porque os princípios de moral não possuem a univocidade dos axiomas matemáticos e os juízos morais não são nem tão seguros, nem tão facilmente comunicáveis quanto os juízos de experiência, as relações que mantêm entre si, que são relações dialéticas, serão mais bem compreendidas se as aproximarmos não das ciências exatas ou naturais, mas do Direito e de sua aplicação. (PERELMAN, 2005, p. 293)

A transitoriedade dos acordos éticos firmados não impede que se cultivem pretensões de universalidade, pois quem propõe normas e padrões de conduta pode almejar a adesão de um auditório universal. Este, porém, não corresponde ao conjunto dos habitantes do planeta, constituindo-se em representação feita acerca do alcance das teses propostas. Para Perelman e Olbrechts-Tyteca (2005), trata-se de uma hipótese de trabalho que orienta o discurso do orador ${ }^{2}$. Em vista disso, no campo da ética, argumentar em defesa de determinadas teses significa submetê-las constantemente ao teste de universalização, o qual não é, senão, o teste da crítica feita por homens e instituições concretas:

A encarnação do auditório universal varia com os séculos, com as épocas, com os progressos da ciência, etc. O que foi considerado normal, válido universalmente em tal época não o foi mais noutra época; isso quer dizer que essa idéia do auditório universal sempre é uma idéia situada histórica, social, psicologicamente. (idem, p. 144)

A partir daí, pode-se perceber que a ética argumentativa defendida por Perelman não pretende sancionar regras infalíveis que venham a se impor aos diferentes povos e culturas ou a todos os seres dotados de razão. Isso a afasta do imperativo categórico de Kant, que se baseia em uma concepção unitária da verdade moral e da razão prática. Na visão perelmaniana, nem a verdade moral é una e universal nem a razão prática é a mesma para todos, já que é concebida segundo um critério de razoabilidade que baliza as decisões dos indivíduos dotados de livre escolha. Se para Kant, por exemplo, não mentir é um imperativo categórico que baliza as ações dos seres morais em quaisquer circunstâncias, para Perelman mentir com o intuito de salvar vidas humanas ameaçadas por um regime político discricionário é considerado uma ação moral, pois é balizada pela noção de razoabilidade:

Enquanto o racional se refere, de um modo variável (...), a verdades eternas e imutáveis, a um direito ou a uma moral universalmente válidos, a provas coercivas, ao espírito sistemático, ao uso dos melhores meios com vistas a um dado fim, o razoável é uma noção mais vaga, com conteúdo condicionado pela história, pelas tradições, pela cultura de uma comunidade. $\mathrm{O}$ que pode ser considerado razoável uma sociedade, numa época, pode deixar de sê-lo noutra sociedade ou noutra época. (PERELMAN, 2005, p. 253)

Com base nas considerações apresentadas, o trabalho com a ética no contexto escolar será discutido na perspectiva de apontar como as noções de pluralismo e de argumentação podem contribuir para modificar a visão, ainda forte no ensino de hoje, de que o aluno não se constitui em sujeito do diálogo. 


\section{Ética no contexto escolar: pluralismo e argumentação}

A importância da educação escolar, na formação da criança e do adolescente, tem sido destacada por diferentes autores no curso do pensamento ocidental, contudo a visão de que os processos educativos se voltam para sujeitos cujas identidades precisam ser consideradas, nem sempre é algo de fácil aceitação. Dewey (1978) chamou a atenção para o fato de que o raciocínio da criança não é primitivo nem errôneo, mas diferente do modo de pensar do adulto. Em vista disso, não há porque considerar a existência de um déficit moral na mentalidade do aprendiz, havendo apenas a necessidade de promover mudanças no modo de encarar a personalidade infantil. Estas passam pela promoção da aprendizagem, a partir do desenvolvimento da criatividade e da capacidade crítica do aluno, afastando-se das metodologias de ensino que privilegiam a memorização de conceitos e a repetição exaustiva de exercícios.

Em um ambiente motivador dos interesses da criança, no qual suas escolhas sejam respeitadas, a disciplina é vista como consequência e não como princípio regulador, não sendo preciso, portanto, impor regras de comportamento. Hansen (2007) destaca com propriedade que para Dewey não deveria haver separação entre os aspectos relativos à cognição e aqueles ligados à educação moral, de modo que não caberia às disciplinas escolares tomar esta última como um objeto à parte, isolado dos temas que abordam. O mais significativo reside no processo de desenvolvimento do caráter, o qual é suscetível de aperfeiçoamento durante toda a vida:

O fim não é jamais um fim de estrada ou um limite a ser atingido, é antes o processo ativo pelo qual se consegue transformar a situação existente. Não a perfeição como um alvo final, mas o processo permanente de aperfeiçoamento, maturação e correção é que é o alvo da vida. A honestidade, a operosidade, a temperança, a justiça, como a saúde, a riqueza e a instrução não são bens a serem possuídos como o seriam, se expressassem fins fixos a serem atingidos. São direções de mudança na qualidade da experiência. O crescimento, o desenvolvimento em si mesmo é o único "fim" moral. (DEWEY, 1978, p. 176-177)

Ao romper com a concepção teleológica de que a educação sempre prepara para um momento superior da existência, no qual o homem pode usufruir com autonomia e liberdade de tudo aquilo que acumulou ao longo do percurso escolar, Dewey abriu caminhos para se pensar o processo educativo a partir de uma perspectiva dialógica e pluralista que considere o aluno como interlocutor. Esta é também defendida por Sacristán (2005, p. 17), para quem "nas salas de aula repletas, encontramos seres reais com um status em processo de mudança, que estão enraizados em contextos concretos, que têm suas próprias aspirações e que, em muitos casos, não se acomodam à ideia que os adultos haviam feito deles".

No mundo do adulto, entretanto, parece perfeitamente natural e legítimo que o indivíduo dotado de nível de amadurecimento maior estabeleça, a partir dos seus referentes, as regras de conduta a serem seguidas. A criança acaba por ser "definida de acordo com as imagens desejáveis do que se considera infância ideal ou prototípica, é uma construção apoiada em nossas crenças e nos valores que oferecemos a ela ou no destino que entendemos que deve ter"(Ibid., p. 24). O reconhecimento de 
que existem distâncias a serem negociadas, bem como de que a criança e o adolescente possuem vozes capazes de expressar diferentes razões esbarra na concepção segundo a qual educar é, antes de tudo, disciplinar:

O adulto é que concebeu a infância como carência e impôs a trajetória em direção a seu próprio status como narrativa de referência para os menores; um a priori que justificará o poder do maior sobre o menor. $\mathrm{O}$ fato de encarar os menores como imperfeitos e até carentes de "sua razão" dá a ele justificativa para dominá-los e submetê-los ao regime disciplinar prolongado que seu poder legitima. (Ibid., p. 42)

Buscando quebrar com esse tipo de visão, comum entre os professores, os Parâmetros Curriculares Nacionais (PCN) tentaram introduzir nos ensinos Fundamental e Médio inovações pedagógicas visando a valorizar a capacidade do estudante se desenvolver como sujeito autônomo (BRASIL, 1998).

Os PCN foram objeto de muitas críticas por parte dos educadores, sendo as principais as que os apontaram como fruto das políticas neoliberais de agentes como o FMI e o Banco Mundial, as quais resultariam na homogeneização do trabalho pedagógico, desconsiderando as diferenças locais e regionais existentes em um país de dimensões continentais como o Brasil. Cabe dizer, porém, que entre as intenções dos protagonistas da economia de mercado e a elaboração do documento não houve, simplesmente, uma relação de causa-efeito, mas um processo marcado por embates que se refletiram na proposta. Isso fez com que o discurso, em muitas passagens, assumisse um tom diretivo e pragmático, ao passo que, em outras, predominava o caráter problematizador e dialógico.

Considerando o documento em sua totalidade, cabe dizer que apresentou uma crítica importante em relação ao trabalho pedagógico escolar que privilegia apenas o ensino dos conteúdos, chamando a atenção para o fato de que educar é, sobretudo, formar sujeitos capazes de pôr em xeque visões naturalizadas dos valores e das formas de comportamento definidas a priori como corretas. Nessa perspectiva, os PCN assinalaram que apenas expor valores, prescrever regras, formas de conduta e punições para as transgressões que são cometidas não contribui para a formação ética dos estudantes, criticando posturas pedagógicas como as assumidas pela tendência moralista:

A tendência moralista tem a vantagem de ser explícita: os alunos ficam sabendo muito bem quais valores os educadores querem que sejam legitimados. Sabem o que se espera deles. Porém, dois graves problemas aparecem. Um de nível ético: o espírito doutrinador dessa forma de trabalhar. A autonomia dos alunos e suas possibilidades de pensar ficam descartadas, pois a moralidade tende a ser apresentada como conjunto de regras acabadas. (...) Outro grave problema, conseqüência desse autoritarismo, é de nível pedagógico: o método não surte efeito, pois ouvir discursos, por mais belos que sejam, não basta para se convencer de que são válidos. A reflexão e a experiência são essenciais. (Ibid., p. 65)

O autoritarismo mencionado conduz ao estabelecimento de um tipo de monismo axiológico que cerceia a livre circulação de ideias sobre temas polêmicos que, hoje, estão presentes na escola, como por exemplo o aborto, a eutanásia e a ho- 
moafetividade. Tomados em uma perspectiva não problematizadora, os dois primeiros são taxados sumariamente como crimes, sendo rejeitados quaisquer argumentos que não os considerem desse modo. A homoafetividade, por sua vez, é rechaçada como comportamento "antinatural", o qual ofende às leis eternas estabelecidas pelo $\mathrm{Ser} \mathrm{Su}$ premo. Perelman (2005), entretanto, salienta que, quando a instância divina é invocada como fundamento das normas morais, a ética fica subordinada à teologia, o que não se coaduna com as sociedades seculares e com o caráter laico da educação pública.

A secularização pode ser compreendida como processo por meio do qual as sociedades foram se libertando da tutela da Igreja e constituindo instituições regidas por normas não submetidas aos preceitos considerados sagrados. $\mathrm{Na}$ Europa, esse processo teve impulso com o Iluminismo e com a Revolução Francesa. No Brasil, segundo Cunha (2011), com a Proclamação da República em 1889, deu-se a separação política entre a Igreja e o Estado, contudo em nossa história republicana sempre houve colaboração recíproca entre essas duas esferas, a qual culminou, no período do regime militar (1964-1988), na ênfase governamental à disciplina Educação Moral e Cívica. Cunha (ibid.) ressalta que tal disciplina consistiu em uma fusão do pensamento católico conservador com a doutrina de segurança nacional, consoante as prescrições da Escola Superior de Guerra. Nessa perspectiva, visões diferenciadas quanto à organização familiar e à sexualidade eram consideradas ofensivas à sociedade, não devendo ser toleradas.

Em contrapartida, em uma visão pluralista, a tolerância com respeito às diferenças é condição fundamental para a convivência. Mas o que significa ser tolerante? Apenas aceitar formalmente o diferente, não agredí-lo ou insultá-lo, mas manter-se distante dele como se fosse portador de alguma doença contagiosa? Segundo Möller (2008, p. 104) "A tolerância pressupõe a reciprocidade, o mútuo reconhecimento do direito do outro a possuir, crer e manifestar sua doutrina moral, concepção de bem ou estilo de vida particular". A mesma autora defende ainda que "cumpre afirmar o pluralismo não apenas como fato, mas como valor: o pluralismo entendido como algo desejável no âmbito das sociedades, a defesa da diferença como valor ético". (Ibid., p. 102).

Sem dúvida, o exercício do pluralismo e a problematização das diferenças não é tarefa fácil no contexto escolar. Muitas vezes, professores e/ou gestores fazem referência a um tempo "perdido" em que as regras disciplinares não eram questionadas, manifestando clara preferência por uma formação ética de cunho heterônomo. A fixação no passado constitui-se, porém, em meio cômodo de evitar a discussão, preterindo facilmente determinado status quo em função de outro. Como frisam Perelman e Olbrechts-Tyteca (2005, p.278): "Em geral, os quadros da idade de ouro, passada ou futura, do paraíso perdido ou esperado, trate-se dos bons velhos tempos ou da felicidade que se encontra alhures, servem para desqualificar a época e o país em que se vive”.

Em outras ocasiões, a escola atribui à família a responsabilidade maior pela falta de formação ética dos alunos. Tal transferência de responsabilidades não atenta para o fato de que o comportamento exibido pelos estudantes possa resultar do conflito entre visões distintas (a da família e/ou a do grupo social) e a preconizada pela escola, tomada sempre como referência ética. Contrapondo-se a isso, Severino (2011, p. 147) salienta que: 
De outro lado, a educação não deve impor, via mecanismos opressores, os valores consagrados pelas morais históricas, pois assim fazendo, não cria condições para que os estudantes construam, vivenciem, sua autonomia pessoal. Toda imposição ideológica e doutrinária aliena, submete, oprime. A escola não pode agir como uma igreja ou como um partido. Por isso mesmo, em que pesem as limitações, a mediação para a formação ética dos aprendizes passa necessariamente pelo esclarecimento, ou seja, embora não baste saber, é preciso compreender. Compreender aqui significa vivenciar um saber que não apenas toca o intelecto, mas também move a vontade, desvelando um sentido valorativo, despertando a sensibilidade ao nexo desse valor ao valor da dignidade humana.

O tratamento das questões éticas, na escola, pede um trabalho integrado entre docentes, gestores e responsáveis pelos alunos. A construção de uma escola plural, democrática e comprometida com processos formativos voltados para a constituição de uma visão crítica sobre a realidade passa pelo respeito às diferenças de natureza filosófica, política, religiosa, etc., que caracterizam os sujeitos, pela compreensão de que há distâncias a negociar, pois o contexto escolar não é imune às relações de poder hierarquizadas existentes na sociedade, nem às influências das redes de interesse que a permeiam.

\section{Considerações finais}

As reflexões e indagações, aqui apresentadas, não pretenderam esgotar o tema, mas contribuir para o debate acerca do trabalho com a ética na escola hoje. Tal trabalho requer o exame constante dos procedimentos pedagógicos adotados, tendo em vista que existem distâncias a negociar entre as visões de quem educa (professores, gestores e responsáveis) e as visões dos alunos. Por meio da problematização do que é admitido como "certo" ou "justo" por esses segmentos, é possível discutir normas, hábitos, valores e formas de conduta e assim chegar a acordos que possam regular a convivência no contexto escolar.

Naturalmente, a ideia de celebrar acordos remete à adoção de uma postura que se afasta do adultocentrismo característico das concepções educacionais que tomam a criança e o adolescente como indivíduos carentes de compreensão e de moralidade, precisando, portanto, ser disciplinados. Isso não quer dizer que o conjunto das experiências vividas pelos mais velhos seja irrelevante, mas considerá-lo como padrão inquestionável ou referente único que se pode impor aos mais jovens é assumir uma postura monista, semelhante a das igrejas ou partidos cujos discursos se apresentam como espelhos da verdade.

Conforme foi comentado, a escola não cumpre bem seu papel educativo quando se converte em lugar de doutrinação, sendo, portanto, mais conveniente para a formação de indivíduos autônomos e críticos argumentar a favor daquilo que se defende como ético, ao invés de simplesmente prescrevê-lo. Embora as concepções monistas possam proporcionar uma espécie de "chão firme" em função das respostas categóricas que costumam dar e das interdições sumárias que postulam, a adoção de uma perspectiva pluralista que promova o efetivo diálogo entre as diferenças permite que os indivíduos se tornem reciprocamente tolerantes. 
Ao empregar o termo tolerância, é preciso salientar que ele pode ser compreendido de um modo preventivo, isto é, que não dá margem à ocorrência de agressões simplesmente porque os diferentes permanecem em seus espaços próprios, ou então de um modo interativo. Neste, o outro deixa de ser o elemento estranho para se tornar sujeito do diálogo, o qual pode enriquecer o que pensamos com seus pensamentos e, reciprocamente, ser enriquecido por aquilo em que acreditamos. Tal reciprocidade não faz sentido se for considerada como regra formal de boa conduta, mas adquire relevância quando as ações de falar e de ouvir, efetivamente, se convertem em momentos complementares em um processo dialógico.

$\mathrm{Na}$ escola de hoje, questões ligadas aos chamados direitos sexuais e reprodutivos, como o aborto e a homoafetividade, não podem mais ser vistas como tabus ou como situações isoladas que se resolvem a portas fechadas. Discuti-las não significa incentivar ou legitimar certos procedimentos e atitudes, mas compreender que a humanidade do homem não é medida pelo enquadramento em moldes fixados pelas tradições culturais e/ou religiosas. Para além delas, existe o respeito pela alteridade, o qual se constrói na interlocução, no embate argumentativo entre pontos de vista conflitantes.

Tal perspectiva não assume para si a tarefa de conferir à ética papel redentor, ou seja, capaz de livrar totalmente a sociedade futura de males como a prática da violência (física e verbal), da discriminação, do preconceito, etc. Por mais que haja boas intenções, haverá sempre distâncias a negociar no curso da existência social. Além disso, a reflexão e o exercício da crítica, da autonomia e da liberdade de escolha não são aquisições inalienáveis, mas alteram-se conforme os contextos relacionais estabelecidos pelos homens.

\section{Referências}

BRASIL. Ministério da Educação. Parâmetros curriculares nacionais: terceiro e quarto ciclos. Brasília: MEC/SEF, 1998, 436p.

CUNHA, L. A. Confessionalismo versus laicidade na educação brasileira: ontem e hoje. Visoni Latino Americane. Trieste (Itália), ano III, n. 4, jan., 2011.

DEWEY, J. A filosofia em reconstrução. São Paulo: Companhia Editora Nacional, 1958, . Vida e educação. São Paulo: Melhoramentos, 1978, 113p.

HANSEN, D. T. O conhecimento moral como um objetivo para a educação: John Dewey. Educação e cultura contemporânea. Rio de Janeiro, v. 4, n. 8, p. 23-36, jul./dez., 2007.

KANT, I. Crítica da razão prática. Lisboa: edições setenta, 1997a.

MILL, J. S. Utilitarismo. Lisboa: Gradiva, 2005.

MÖLLER, L. L. Pluralismo e tolerância: valores para a bioética. Revista do Hospital das Clínicas de Porto Alegre. Porto Alegre, v. 28, n. 2, p. 101-109, 2008.

PERELMAN, C. La philosophie du pluralisme et la nouvelle réthorique. Revue Internationale de Philospohie, n. 127-128, p. 5-17, 1979.

. Ética e direito. São Paulo: Martins Fontes, 2005. 
PERELMAN, C., OLBRECHTS-TYTECA, L. Tratado da argumentação: a nova retórica. 2a. ed., São Paulo: Martins Fontes, 2005.

PLATÃO. La republique. Paris: Garnier-Flammarion, 1966.

. Fedro. Diálogos. São Paulo: Edipro, 2008, p. 31-110.

SACRISTÁN, J. G. O aluno como invenção. Porto Alegre: Artmed, 2005.

SAMARANCH, F. Quatro ensayos sobre Aristóteles. México, Madrid, Buenos Aires: Fondo de Cultura Econômica, 1991.

SEVERINO, A. J. Formação e atuação dos professores: dos seus fundamentos éticos. In: SEVERINO, F. E. Santos (Org.). Ética e formação de professores. São Paulo: Cortez, 2011, p. 130-149.

\section{Notas}

${ }^{1} \mathrm{O}$ termo é derivado de mônada, que em uma acepção leibniziana significa totalidade em si mesma.

${ }^{2}$ No âmbito da abordagem conduzida por Perelman e Olbrechts-Tyteca (2005), orador é todo aquele que defende uma ou mais teses visando à adesão de determinado público, o qual se constitui em seu auditório.

* Professor Doutor da Universidade Federal do Rio de Janeiro, Faculdade de Educação, Departamento de Fundamentos da Educação - Rio de Janeiro, Rio de Janeiro, Brasil.

\section{Correspondência}

Renato Jose de Oliveira - Universidade Federal do Rio de Janeiro, Faculdade de Educação, Departamento de Fundamentos da Educação. Av. Pasteur 250 - fundos, Urca, CEP: 22290-240 - Rio de Janeiro, Rio de Janeiro - Brasil.

E-mail: rj-oliveira1958@uol.com.br

Recebido em 18 de junho de 2013

Aprovado em 12 de novembro de 2013 
